\title{
Introduction to Special Hawai'i Coral Reef Initiative Research Program Volume
}

In 1998, The Hawai's Coral Reef Initiative Research Program (HCRI-RP) was established to support scientific research and monitoring to enhance the state's capacity to manage its coral reef resources. HCRI-RP is jointly managed by Hawai'i's Department of Land and Natural Resources/Division of Aquatic Resources (DAR) and the University of Hawai'i (UH) through a Management Committee. Currently, the Committee has three representatives from DAR, one from the U.S. Fish and Wildlife Service, two from UH, and one from the Pacific Science Association/Bishop Museum.

The papers in this special issue are based on research and monitoring projects supported by HCRI-RP during its first $4 \mathrm{yr}$ (1998-2002). These projects were selected by the Management Committee to provide information to resource managers and contribute to our understanding of coastal processes and threats to the health of coral reef ecosystems.

HCRI-RP supported the establishment of a standardized annual coral monitoring protocol allowing for comparison among sites from 1998 to 2002. Commonly known as the Coral Reef Assessment and Monitoring Project (CRAMP), the project's goal was to identify both natural and human factors contributing to the stability, decline, or recovery of Hawai'i's corals. In this volume, Brown et al. describe the development of CRAMP's methodology designed to detect an absolute change of $10 \%$ in benthic cover with high statistical power. Using this methodology, Jokiel et al. report on the project's findings, particularly the importance of wave energy, island age, rugosity, and sediment on coral reef community structure.

Harvesting for the aquarium trade is one source of fishing pressure in Hawai'i. HCRI$\mathrm{RP}$ sponsored what has come to be known as

Pacific Science (2004), vol. 58, no. 2:143-144 (C) 2004 by University of Hawai'i Press the West Hawai'i Aquarium Project from 1998 to 2003 to determine the status of aquarium fish populations along the Kona coast of the island of Hawai' $i$ and to assess the effectiveness of nine fish replenishment areas established by the state. Tissot et al. report that there is a significant increase of aquarium fishes in reserves, most likely due to the high recruitment of fish observed in 2001-2002.

In 1998-1999, HCRI-RP sponsored a multifaceted project designed to examine the fine-scale processes affecting health and stability of Hawaiian reefs. Part of that project was to determine the feasibility of transplanting herbivorous fishes as a means to control the invasive alga Dictyosphaeria cavernosa. Conklin and Stimson found that fishes did not remain on the reefs to which they were added, despite the addition of large numbers of fishes. The authors speculate that this was due to habitat degradation and the resulting lack of shelter.

The remote and vast nature of the northwestern Hawaiian Islands (NWHI) poses unique challenges to researchers and managers. Given the changing federal and state roles within the region, HCRI-RP cosponsored the first Northwestern Hawaiian Islands Reef Assessment and Monitoring Program (NOW-RAMP) and subsequent data analysis in 2000-2002. Preskitt et al. describe a macroscale rapid ecological assessment technique for algal assemblages as a necessary component for monitoring across the region's benthic communities. Maragos et al. report results from rapid coral assessments in the NWHI.

Cesar and van Beukering discuss the economic value of Hawai'i's reefs, based on a project funded by HCRI-RP during 20012002. Hawai'i's coastal reefs generate an estimated $\$ 800$ million each year in gross revenues (or, \$364 million in added value) for the state's economy. Over $50 \mathrm{yr}$, reefs surrounding the main Hawaiian Islands will have contributed over $\$ 18$ billion in added value to the local economy. 
As a result of hardening, streams in Hawai'i deliver sediment and nutrients to the nearshore environment in an altered way. Therefore, in 2001-2002, HCRI-RP sponsored Laws and Roth to look at the impact of stream channelization and how to mitigate this degradation. Their results demonstrate that hardened streams have greater downstream delivery of nitrate than nonmodified streams. This is effectively a fast-release fertilizer for algae. If the hardening process extends to the mouth of the stream, the result is an unnaturally high level of nitrogen delivered into coastal waters.

Also in 2001-2002, HCRI-RP funded a project to assess the relative contributions of natural and anthropogenic stress on coral reef ecosystems in Hawai'i. Anthropogenic impacts on the nearshore water column are particularly important in areas protected from high wave energy, generally embayments and lagoons. Dollar and Grigg conclude that resource managers should concentrate their management efforts on areas where circulation is confined, especially in areas where land uses result in increased input of materials to the nearshore environment.

Researchers sponsored by HCRI-RP during 2001-2002 investigated the impact of climate variability on coral reef ecosystems. Without a long-term perspective on reef evolution, managers may not grasp full impacts and significances of locally critical processes. Rooney et al. confirm that high wave action, tropical storms, and hurricanes have affected coral growth and accretion historically. The frequency of such events is strongly influenced by seasonal and interannual climate variability, particularly El Niño events. If El Niño-like conditions are more prevalent in the future because of global climate change, growth of coral reefs in Hawai'i could be influenced.

Waikīīi, one of Hawai'i's most famous and profitable tourist attractions, is imperiled by the alien alga species Gracilaria salicornia.
This alga dominates the inshore regions of Waikiki adjacent to the Waikiki War Memorial and Natatorium, creating tangled, floating mats. Since its introduction some $30 \mathrm{yr}$ ago, Gracilaria salicornia has grown unchecked and now is found from Diamond Head to $\mathrm{Ala}$ Moana. Smith et al. present results from their 2001-2002 HCRI-RP project, which investigated practical management options to address this threat. The growth rates, ability to fragment, physical tolerance to fresh water and desiccation, and low herbivory make it clear that a large-scale, dedicated effort is needed to control $G$. salicornia.

Taken together, these papers represent monitoring activities and research projects sponsored by HCRI-RP aimed at identifying and mitigating threats to Hawai'i's coastal reefs.

Michael Hamnett

University of Hawai'i

Kristine Davidson

University of Hawai' $i$

William Devick

Division of Aquatic Resources

Lucius Eldredge

Bishop Museum

Kevin Foster

U.S. Fish and Wildlife Service

Jo-Ann Leong

University of Hawai'i

Robert Nishimoto

Division of Aquatic Resources

Francis Oishi

Division of Aquatic Resources

Celia Smith

University of Hawai'i 